\begin{tabular}{|c|l|}
\hline Title & $\begin{array}{l}\text { BS69 cooperates with TRAF3 in the regul ation of Epstein-Barr virus derived LMP1/CTA R1-induced NF-K B } \\
\text { activation }\end{array}$ \\
\hline Author(s) & $\begin{array}{l}\text { Ikeda, Osamu; Miyasaka, Y uto; Yoshida, Ryuji; Mizushima, A kihiro; Oritani, Kenji; Sekine, Y uichi; Kuroda, Makoto; } \\
\text { Y asui, Teruhito; Fuji imuro, Masahiro; Muromoto, Ryuta; Nanbo, A suka; Matsuda, Tadashi }\end{array}$ \\
\hline Citation & $\begin{array}{l}\text { FEBS Letters, 584(5), 865-872 } \\
\text { https://doi.org/10.1016/.febslet.2010.01.060 }\end{array}$ \\
\hline Issue Date & 2010-03-05 \\
\hline Doc URL & http://hdl.handle.net/2115/42639 \\
\hline Type & article (author version) \\
\hline File Information & matsuda_FEBS.pdf \\
\hline
\end{tabular}

Instructions for use 


\section{Title: BS69 cooperates with TRAF3 in the regulation of Epstein-Barr virus-derived LMP1/CTAR1-induced NF- $\square$ B activation}

Authors: Osamu Ikeda ${ }^{1}$, Yuto Miyasaka ${ }^{1}$, Ryuji Yoshida $^{1}$, Akihiro Mizushima ${ }^{1}$, Kenji

Oritani $^{2}$, Yuichi Sekine ${ }^{1}$, Makoto Kuroda ${ }^{1}$, Teruhito Yasui ${ }^{3}$, Masahiro Fujimuro ${ }^{4}$, Ryuta Muromoto $^{1}$, Asuka Nanbo ${ }^{1}$, and Tadashi Matsuda ${ }^{1, *}$

Affiliation: ${ }^{1}$ Department of Immunology, Graduate School of Pharmaceutical Sciences Hokkaido University, Sapporo 060-0812 Japan, ${ }^{2}$ Department of Hematology and Oncology, Graduate School of Medicine, Osaka University, 2-2 Yamada-oka, Suita, Osaka 565-0871, Japan, ${ }^{3}$ Department of Molecular Immunology, Research Institute for Microbial Diseases, Osaka University, 3-1 Yamada-oka, Suita, Osaka 565-0871, Japan, ${ }^{4}$ Department of Molecular Cell Biology, Interdisciplinary Graduate School of Medicine and Engineering, University of Yamanashi, Chuo 409-3898, Japan.

*Address for manuscript correspondence: Dr. Tadashi Matsuda, Department of Immunology, Graduate School of Pharmaceutical Sciences, Hokkaido University, KitaKu Kita 12 Nishi 6, Sapporo 060-0812, Japan TEL: 81-11-706-3243, FAX: 81-11-7064990,E-mail: tmatsuda@pharm.hokudai.ac.jp

Running title: Physical and functional interactions between BS69 and LMP1/CTAR1 Key words: BS69; EBV; LMP1; TRAF3; NF- $\square \mathrm{B}$; transcription 


\begin{abstract}
Epstein-Barr virus latent membrane protein 1 (LMP1) activates NF- $\square$ B signaling pathways through two C-terminal regions, CTAR1 and CTAR2. Previous studies have demonstrated that BS69, a multidomain cellular protein, regulates LMP1/CTAR2mediated NF- $\square$ B activation by interfering with the complex formation between TRADD and LMP1/CTAR2. Here, we found that BS69 directly interacted with the LMP1/CTAR1 domain and regulated LMP1/CTAR1-mediated NF- $\square$ B activation and subsequent IL-6 production. Regarding the mechanisms involved, we found that BS69 directly interacted with TRAF3, a negative regulator of NF- $\square \mathrm{B}$ activation. Furthermore, small-interfering RNA-mediated knockdown experiments revealed that TRAF3 was involved in the BS69-mediated suppression of LMP1/CTAR1-induced NF- $\square \mathrm{B}$ activation.
\end{abstract}

Keywords: EBV, LMP1, BS69, NF- $\square \mathrm{B}$, TRAF3 


\section{Introduction}

Epstein-Barr virus (EBV) is strongly linked to the development of multiple malignancies, including post-transplant lymphoma, Hodgkin disease and nasopharyngeal carcinoma. EBV-encoded latent membrane protein 1 (LMP1) is expressed in many EBV-associated tumor cells and is responsible for the majority of their altered cellular growth properties. Structurally, LMP1 is an integral membrane protein of 386 amino acids (aa) that consists of a short cytoplasmic N-terminal domain (aa 1-24), six transmembrane domains (aa 25-186) and a long cytoplasmic C-terminal tail (aa 187-386) [1-3]. The cytoplasmic C-terminal tail contains two C-terminal activation regions (CTARs), CTAR1 and CTAR2 [1,4]. Signals through these two CTAR domains have been reported to induce p100 and p105 NF- $\square \mathrm{B}$ precursors and generate p52 and p50 subunits, respectively [5,6], indicating that LMP1 is involved in both canonical and non-canonical activation of NF- $\square$ B pathways. CTAR1 contains a tumor necrosis factor receptor (TNFR)-associated factor (TRAF)-binding motif, and can bind to TRAF1, TRAF2, TRAF3 and TRAF5 [1,7-10]. CTAR2 interacts with TNFRassociated death domain protein (TRADD), receptor-interacting protein (RIP) $[11,12]$ and BS69 [13]. These CTAR1- and CTAR2-associated molecules have the ability to induce or suppress LMP1-mediated NF- $\square$ B activation. Recently, we identified STAP-2, an adaptor protein, as a new binding partner of both CTAR1 and CTAR2, and demonstrated that STAP-2 negatively regulates LMP1-mediated NF- $\square$ B activation [14].

BS69, a multidomain cellular protein containing PHD, Bromo, PWWP and MYND domains, was originally identified as an adenovirus E1A-binding protein that inhibits the transactivation function of E1A [15]. Furthermore, the C-terminal MYND domain 
of BS69 was shown to bind to the PXLXP motif existing in E1A, the EBV-encoded EBNA2 and the Myc-related cellular protein MGA [16]. Importantly, BS69 interacts with EBV-encoded LMP1 through its MYND domain and acts as a scaffold protein in the LMP1-mediated JNK pathway [13] by interacting with TRAF6. In addition, we previously reported that BS69 is able to negatively regulate LMP1-mediated NF- $\square \mathrm{B}$ activation by displacing TRADD from the CTAR2 domain of LMP1 [17].

In the present study, we newly found that BS69 directly interacts with the LMP1/CTAR1 domain and downregulates LMP1/CTAR1-mediated NF- $\square$ B activation. We further found that TRAF3 directly interacts with BS69 and is involved in the BS69mediated suppression of LMP1/CTAR1-induced NF- $\square$ B activation. Taken together, BS69 is likely to act as an endogenous negative regulator of both canonical and noncanonical NF- $\square$ B activation mediated by LMP1. 


\section{Materials and methods}

\subsection{Reagents and antibodies}

Expression vectors for BS69 and NF- $\square \mathrm{B}-\mathrm{LUC}$ were kindly provided by H. Shibuya (Tokyo Medical and Dental University, Tokyo, Japan) and T. Fujita (Kyoto University, Kyoto, Japan)[17, 18, 19]. Epitope-tagged LMP1 and a series of TRAF constructs were described previously [14]. The following primary antibodies were obtained commercially: anti-p52, anti-Bcl-2, anti-nucleoporin, anti-TRAF3 and anti-Myc antibodies (Santa Cruz Biotechnology, Santa Cruz, CA); anti-FLAG mAb (M2) and anti-HA antibody (Sigma-Aldrich, St. Louis, MO); and anti-actin mAb (Chemicon International, Temecula, CA).

\subsection{Cell culture and transfection}

A human cervix carcinoma cell line (HeLa), human embryonic kidney carcinoma cell line (293T) were maintained in DMEM containing 10\% FCS. HeLa cells were transfected using jetPEI (PolyPlus-transfection, Strasbourg, France) according to the manufacturer's instructions. 293T cells were transfected using a standard calcium precipitation protocol [19]. A human B-lymphoblastoid EBV-transformed cell line (SKW6-CL4) was maintained in RPMI1640 containing 10\% FCS.

\subsection{Transfection of small-interfering RNAs (siRNAs) and luciferase assays}

The siRNAs targeting human BS69 (\#1 and \#2) used in this study were as follows:

BS69\#1, 5'-GGAUGAAGUCGGACCACAATT-3'; BS69\#2, 5'-

GAAGUUAUGAAGAGUUCAATT-3'; TRAF3, 5'- 
GGAAGAUUCGCGACUACAATT-3'. HeLa cells were plated on 24-well plates at $2 \times 10^{4}$ cells/well and incubated with an siRNA (15 pM) -Lipofectamine 2000 (Invitrogen, Carlsbad, CA) mixture at $37^{\circ} \mathrm{C}$ for $4 \mathrm{~h}$, followed by the addition of fresh medium containing 10\% FCS. HeLa cells were further transfected with or without NF- $\square \mathrm{B}-\mathrm{LUC}$ with or without LMP1 using jetPEI as described in the section above. At $24 \mathrm{~h}$ after transfection, the cells were harvested and assayed for their luciferase activities using a Dual-Luciferase Reporter Assay System (Promega, Madison, WI) according to the manufacturer's instructions. 293T cells were transfected as described in the section above. The cells were harvested at $36 \mathrm{~h}$ after transfection, lysed in $50 \mathrm{ml}$ of Reporter Lysis Buffer (Promega) and assayed for their luciferase and $\square$-galactosidase activities according to the manufacturer's instructions. Three or more independent experiments were carried out for each assay. Human SKW6-CL4 B cells were transfected with a control siRNA or BS69 siRNA\#2 (100 pM) using a MicroPorator according to the manufacturer's instructions.

\subsection{Immunoprecipitation and immunoblotting}

Immunoprecipitation and western blotting assays were performed as described previously [20]. The immunoprecipitates from cell lysates were resolved by SDS-PAGE and transferred to PVDF membranes (PerkinElmer, Boston, MA). The membranes were then immunoblotted with the different primary antibodies. Immunoreactive proteins were visualized using an enhanced chemiluminescence detection system (Millipore, Bedford, MA).

2.5. RNA isolation, RT-PCR and quantitative real-time PCR 
After cell harvesting, total RNA samples were extracted using Iso-Gen (Nippon Gene, Tokyo, Japan) and subjected to RT-PCR using an RT-PCR High -Plus- Kit (TOYOBO, Tokyo, Japan)[14]. Primers used for RT-PCR were: BS69: 5'GGATATTGGTTGCCAGGAGA-3' (sense)， 5'-GTGCCCATCTCCTGTTTGTT-3' (antisense), interleukin (IL)-6: 5' - ATGAACTCCTTCTCCACAAGCGC-3' (sense), 5'GAAGAAGCCCTCAGGCTGGACTG-3' (antisense), NF- $\square$ B2: 5'GGGTGTCCTGCATGTGACTA-3' (sense)， 5'-AGGGAGAAGGAGCCATCACT-3' (antisense). Quantitative real-time PCR analyses for IL-6, BS69 and control G3PDH mRNA transcripts were carried out using Assays-on-Demand ${ }^{\mathrm{TM}}$ gene-specific fluorescently-labeled TaqMan MGB probes in an ABI Prism 7000 sequence detection system (Applied Biosystems, Foster City, CA).

\subsection{Measurement of IL-6 in the culture supernatants}

Concentrations of IL-6 in culture supernatants from siRNA-transfected HeLa cells were measured by enzyme-linked immunosorbent assay (ELISA) according to manufacturer's instructions (Biosource, Camarillo, USA). 


\section{Results and discussion}

3.1. BS69 interacts with the LMP1/CTAR1 domain and negatively regulates LMP1/CTAR1-induced NF- $\square$ B activation

We previously showed that BS69 suppresses LMP1-induced canonical NF- $\square \mathrm{B}$ activation, which is mediated through the cytoplasmic C-terminal CTAR2 domain of LMP1 [17]. Although BS69 has been believed to bind to the CTAR2 domain, the yeast two-hybrid assays employed the cytoplasmic carboxyl tail of LMP1 (aa 187-386), containing both CTAR1 and CTAR2, as bait [13]. These facts led us to investigate whether BS69 physically and functionally interacts with the LMP1/CTAR1 domain, another functional domain for NF- $\square$ B activation. First, we examined whether BS69 binds to a truncated LMP1 (aa 1-231) lacking the CTAR2 domain. Coimmunoprecipitation experiments were performed using 293T cells transfected with expression vectors for HA-tagged BS69 together with FLAG-tagged LMP1 wild-type (WT), LMP1 (aa 1-231) or empty vector. The immunoprecipitates for LMP1 WT contained BS69 protein (Fig. 1A and B), as expected from previous data [13,17]. Similarly, the immunoprecipitates for LMP1 (aa 1-231) contained BS69 protein, indicating that BS69 was still able to associate with LMP1 in the absence of the CTAR2 domain in 293 T cells.

Next, we investigated the effects of BS69 on LMP1/CTAR1-induced NF- $\square$ B activation using transient reporter assays with NF- $\square$ B-LUC. The NF- $\square$ B-LUC activities were induced by the expression of LMP1 (aa 1-231) in 293 T and HeLa cells (Fig. 1C), although NF- $\square$ B activation induced by LMP1 (aa 1-231) was lower than LMP1 WT. Indeed, LMP1 WT showed approximately 2-3-fold higher activation than LMP1 (aa 1- 
231), when cells were transfected with the same amount of plasmids (data not shown). Importantly, these LMP1/CTAR1-induced NF- $\square$ B-LUC activities were significantly reduced by co-expression of BS69 in a dose-dependent manner, suggesting that BS69 negatively regulates LMP1/CTAR1-induced NF- $\square$ B activation. This inhibitory effect of BS69 was confirmed by experiments using siRNAs that reduced the endogenous expression of BS69 in HeLa cells. HeLa cells were transfected with specific siRNAs for BS69 (\#1 and \#2) or a control siRNA. Total RNA isolated from the transfected cells was subjected to RT-PCR and quantitative real-time PCR analysis, which confirmed a reduction in BS69 mRNA expression (Fig. 1D). We then investigated the effects of the BS69 siRNAs on LMP1/CTAR1-induced NF- $\square$ B activation. As shown in Fig. 1E, siRNA-mediated reduced expression of BS69 resulted in a significant enhancement of the LMP1 (aa 1-231)-induced NF- $\square$ B-LUC activities in these cells. Of importance, NFGB-LUC activation in the BS69 siRNA-treated HeLa cells was slightly enhanced even in the absence of LMP1-expression. There might be the possibility that endogenous BS69 regulates basal NF- $\square$ B activation by interacting with some unknown NF- $\square \mathrm{B}$ activators. At the present time, we do not know the mechanisms of regulation of basal NF- $\square$ B activation by BS69. Further detailed study will be required to clarify this issue.

NF- $\square$ B activation induces the production of inflammatory cytokines, such as IL-6. To confirm the regulation of LMP1/CTAR1-induced NF- $\square$ B activation by BS69, LMP1/CTAR1-induced IL-6 mRNA expression was analyzed in the BS69 siRNAtreated HeLa cells. LMP1 (aa 1-231)-induced IL-6 mRNA expression was augmented in parallel with the decrease in BS69 (Fig. 2A). LMP1 (aa 1-231)-induced synthesis of IL6 protein was also enhanced in BS69 siRNA-transfected HeLa cells (Fig.2B). Taking 
these results together, BS69 acts as a negative regulator of LMP1/CTAR1-induced cytokine expression by interfering with NF- $\square \mathrm{B}$ activation.

Next, we examined the effects of BS69 on LMP1-induced p100/NF- $\square$ B2 processing to p52, which leads to non-canonical NF- $\square$ B activation through the CTAR1 domain of LMP1 [6, 21-23]. As shown in Fig. 2C, siRNA-mediated reduced expression of BS69 resulted in a significant enhancement of LMP1-induced p100/NF- $\square \mathrm{B} 2$ processing to $\mathrm{p} 52$ in the nucleus of these cells. Therefore, BS69 regulates the non-canonical NF- $\square \mathrm{B}$ activation mediated by the CTAR1 domain of LMP1. We also tested the effect of BS69 knockdown in human EBV-positive SKW6-CL4 B cells. Importantly, reduction of endogenous BS69 in SKW6-CL4 cells enhanced p100/NF- $\square$ B2 processing into p52 via the non-canonical pathway and the Bcl-2 content (Fig. 2D). These results indicate that BS69 may act as a modulator for non-canonical NF- $\square$ B activation in HeLa cells and EBV-infected human B cells.

3.2. TRAF3 is involved in the BS69-mediated regulation of LMP1/CTAR1-induced NF- $\square$ B activation

One of the important molecular mechanisms underlying LMP1-induced NF- $\square \mathrm{B}$ activation was investigated based on the fact that LMP1/CTAR1 specifically interacts with TRAFs through a conserved TRAF-binding motif [1, 7-10]. TRAFs are important downstream signaling adaptors for many receptors, such as the TNFR and IL-1 receptor/Toll-like receptor superfamilies, including CD40, and function as docking molecules for proteins involved in TNFR signaling, especially NF- $\square$ B signaling. Therefore, we tested the possible associations of BS69 with a series of TRAFs. 293T cells were transfected with FLAG-tagged TRAF1, TRAF2, TRAF3, TRAF5 or TRAF6 
together with HA-tagged BS69. Western blot analyses with an anti-HA antibody revealed that BS69 physically interacted with all the TRAFs examined (Fig. 3A). We also examined the effects of TRAFs on LMP1WT- and LMP1/CTAR1-induced NF$\square$ B activation in HeLa cells. As shown in Fig. 3B and C, TRAF3 showed a significant suppressive effect on both LMP1WT- and LMP1 (aa 1-231)-induced NF- $\square$ B activation, although TRAF2 showed a small effect on LMP1 (aa 1-231)-induced NF- $\square$ B activation. Furthermore, siRNA-mediated reduction of TRAF3 expression resulted in enhanced LMP1 (aa 1-231)-induced NF- $\square$ B activation (Fig. 3D), although siRNA-mediated reduction of TRAF2 expression did not enhance LMP1 (aa 1-231)-induced NF- $\square$ B activation (data not shown). Therefore, we focused on TRAF3 in regulation of LMP1/CTAR1-induced NF- $\square$ B activation. To assess the functional relevance of the interactions between BS69 and TRAF3 in LMP1/CTAR1-induced NF- $\square$ B activation. HeLa cells were transfected with specific siRNAs for BS69 or TRAF3, or a control siRNA. Reductions in the expression of BS69 or TRAF3 (Fig. 3D) resulted in enhanced LMP1 (aa 1-231)-induced NF- $\square$ B activation, indicating that both BS69 and TRAF3 are involved in the regulation of LMP1/CTAR1-induced NF- $\square \mathrm{B}$ activation in HeLa cells. However, no synergistic effect was observed by combined silencing of BS69 and TRAF3.

We further investigated which domains of TRAF3 mediated the interactions with BS69. HA-tagged BS69 and the respective FLAG-tagged TRAF3 mutants were transiently expressed in $293 \mathrm{~T}$ cells. Immunoprecipitation with an anti-HA antibody followed by western blot analyses with an anti-FLAG antibody revealed that TRAF3

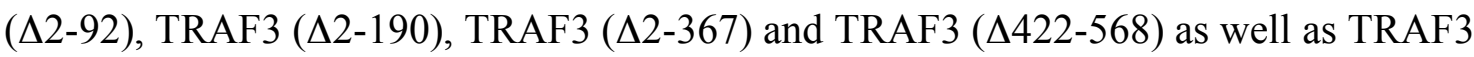
WT were able to bind to BS69. However, TRAF3 (\317-568) lost the ability to bind to 
BS69. These findings suggested that the binding site for BS69 on TRAF3 was mapped to a region (aa 368-421) in the N-terminal of the TRAF-binding domain (Fig. 4B). With regard to domains of TRAF3 mediated the interactions with LMP1/CTAR1, the Cterminal TRAF-binding domain of TRAF3 was clearly essential although the results for the N-terminal RING domain were complicated (data not shown). Therefore, these data demonstrate that TRAF3 directly interacts with the LMP1/CTAR1 and BS69.

Unlike many other TRAF family proteins that enhance NF- $\square$ B activation, TRAF3 has been reported to suppress TNFR family-induced NF- $\square$ B activation and was identified as a negative regulator of NF- $\square$ B by promoting its degradation [24]. Moreover, recent studies have indicated that the B cells in TRAF3 knockout mice develop splenomegaly and lymphadenopathy, in association with hyperglobulinemia and autoimmunity, suggesting a role for TRAF3 in B-cell homeostasis [25,26]. With regard to LMP1 signaling, experiments involving TRAF3 overexpression have indicated that TRAF3 inhibits the NF- $\square$ B activation induced by LMP1. Furthermore, TRAF3 has been shown to negatively regulate LMP1 signaling by displacing TRAF1 and TRAF2 from CTAR1 [8]. In addition, TRAF3 is known to regulate LMP1 signaling through direct interactions with CTAR1 and indirect interactions with CTAR2 [25]. Based on the above information, we examined the effects of combined knockdown of BS69 and TRAF3 on the LMP1/CTAR1-induced NF- $\square$ B activation in HeLa cells. Interestingly, the reduction of endogenous TRAF3 caused a significant increase in LMP1 (aa 1-231)induced NF- $\square$ B activation but no significant effect of BS69 siRNA-mediated enhancement of LMP1 (aa 1-231)-induced NF- $\square$ B activation (Fig. 3D), indicating that BS69 fails to suppress LMP1/CTAR1-induced NF- $\square$ B activation in the absence of 
TRAF3. Therefore, a BS69-TRAF3 complex may interact with LMP1/CTAR1 and be responsible for the regulation of LMP1/CTAR1-induced NF- $\square$ B activation. Taken together, these findings indicate that BS69 cooperates with TRAF3 in the regulation of LMP1/CTAR1-induced NF- $\square$ B activation.

\subsection{Concluding remarks}

In our previous study, we showed that BS69 suppresses LMP1-induced NF- $\square \mathrm{B}$ activation by competing with the complex formation between TRADD and LMP1/CTAR2 [17]. Here, we have demonstrated novel functions of BS69, namely that it interacts with LMP1/CTAR1 and negatively regulates LMP1/CTAR1-mediated NF$\square \mathrm{B}$ activation. Regarding the inhibitory mechanisms, we found cooperative effects between BS69 and TRAF3. Therefore, BS69 can inhibit LMP1-induced NF- $\square \mathrm{B}$ activation mediated through both the CTAR1 and CTAR2 domains. These suppressive effects of BS69 may be similar to the case for STAP-2, which we previously reported as a negative regulator of LMP1/CTAR1- and LMP1/CTAR2-induced NF- $\square$ B activation. However, the molecular mechanisms underlying these effects are a little different. BS69 equally bound to all TRAF family proteins examined (TRAF1, TRAF2, TRAF3, TRAF5 and TRAF6), while STAP-2 strongly interacted with TRAF1 and TRAF3 [14]. The binding site for STAP-2 on TRAF3 was mapped to a narrow region (aa 317-367) between a leucine-zipper domain and a TRAF-binding domain [14], while the binding site for BS69 was mapped to a region (aa 368-421) in the N-terminal portion of the TRAF-binding domain. Moreover, LMP1 expression upregulated STAP-2 expression, suggesting that STAP-2 plays a role in the defense of host cells against EBV after infection. In contrast, BS69 is constitutively expressed and may function in the defense 
of host cells against EBV under steady-state conditions. Our proposed mechanisms for the actions of BS69 on LMP1 signaling are illustrated in Fig. 4C. Our data suggest that BS69 may be a novel candidate for antiviral therapies aimed at regulating the EBV LMP1-induced NF- $\square$ B and JNK pathways. 


\section{Acknowledgements}

We thank S. Kamitani for technical assistance. This study was supported in part by Grant-in-Aid for scientific research from Ministry of Education, Culture, Sports, Science and Technology of Japan. 


\section{References}

[1] Kieff, E. (1996) Epstein-Barr virus and its replication in: Fields Virology (Field, D.M., Knipe, D.M. and Howley, P.M., Eds.), vol. 2, 3rd ed, pp. 2343-2396, Raven Press, New York.

[2] Liebowitz, D., Wang, D. and Kieff, E. (1986) Orientation and patching of the latent infection membrane protein encoded by Epstein-Barr virus. J. Virol. 58, 233-7.

[3] Li, H.P. and Chang, Y.S. (2003) Epstein-Barr virus latent membrane protein 1: structure and functions. J. Biomed. Sci. 10, 490-504.

[4] Huen, D.S., Henderson, S.A., Croom-Carter, D. and Rowe, M. (1995) The Epstein-Barr virus latent membrane protein-1 (LMP1) mediates activation of NF-kappa B and cell surface phenotype via two effector regions in its carboxyterminal cytoplasmic domain. Oncogene 10, 549-60.

[5] Laherty, C.D., Hu, H.M., Opipari, A.W., Wang, F. and Dixit, V.M. (1992) The Epstein-Barr virus LMP1 gene product induces A20 zinc finger protein expression by activating nuclear factor kappa B. J. Biol. Chem. 267, 24157-60.

[6] Luftig, M., Yasui, T., Soni, V., Kang, M.S., Jacobson, N., Cahir-McFarland, E., Seed, B. and Kieff, E. (2004) Epstein-Barr virus latent infection membrane protein 1 TRAF-binding site induces NIK/IKK alpha-dependent noncanonical NF-kappaB activation. Proc. Natl. Acad. Sci. U S A 101, 141-6.

[7] Brodeur, S.R., Cheng, G., Baltimore, D. and Thorley-Lawson, D.A. (1997) Localization of the major NF-kappaB-activating site and the sole TRAF3 binding site of LMP-1 defines two distinct signaling motifs. J. Biol. Chem. 272, 19777-84.

[8] Devergne, O., Hatzivassiliou, E., Izumi, K.M., Kaye, K.M., Kleijnen, M.F., Kieff, E. and Mosialos, G. (1996) Asciation of TRAF1, TRAF2, and TRAF3 with an Epstein-Barr virus LMP1 domain important for B-lymphocyte transformation: role in NF-kappaB activationso. Mol. Cell. Biol. 16, 7098-108.

[9] Kaye, K.M., Devergne, O., Harada, J.N., Izumi, K.M., Yalamanchili, R., Kieff, E. and Mosialos, G. (1996) Tumor necrosis factor receptor associated factor 2 is a mediator of NF-kappa B activation by latent infection membrane protein 1, the Epstein-Barr virus transforming protein. Proc. Natl. Acad. Sci. U S A 93, 1108590. 
[10] Mosialos, G., Birkenbach, M., Yalamanchili, R., VanArsdale, T., Ware, C. and Kieff, E. (1995) The Epstein-Barr virus transforming protein LMP1 engages signaling proteins for the tumor necrosis factor receptor family. Cell 80, 389-99.

[11] Izumi, K.M. and Kieff, E.D. (1997) The Epstein-Barr virus oncogene product latent membrane protein 1 engages the tumor necrosis factor receptor-associated death domain protein to mediate B lymphocyte growth transformation and activate NF-kappaB. Proc. Natl. Acad. Sci. U S A 94, 12592-7.

[12] Izumi, K.M., Cahir McFarland, E.D., Ting, A.T., Riley, E.A., Seed, B. and Kieff, E.D. (1999) The Epstein-Barr virus oncoprotein latent membrane protein 1 engages the tumor necrosis factor receptor-associated proteins TRADD and receptor-interacting protein (RIP) but does not induce apoptosis or require RIP for NF-kappaB activation. Mol. Cell. Biol. 19, 5759-67.

[13] Wan, J. et al. (2006) BS69, a specific adaptor in the latent membrane protein 1mediated c-Jun N-terminal kinase pathway. Mol. Cell. Biol. 26, 448-56.

[14] Ikeda, O. et al. (2008) STAP-2 negatively regulates both canonical and noncanonical NF-kappaB activation induced by Epstein-Barr virus-derived latent membrane protein 1. Mol. Cell. Biol. 28, 5027-42.

[15] Hateboer, G., Gennissen, A., Ramos, Y.F., Kerkhoven, R.M., Sonntag-Buck, V., Stunnenberg, H.G. and Bernards, R. (1995) BS69, a novel adenovirus E1Aassociated protein that inhibits E1A transactivation. EMBO J. 14, 3159-69.

[16] Ansieau, S. and Leutz, A. (2002) The conserved Mynd domain of BS69 binds cellular and oncoviral proteins through a common PXLXP motif. J. Biol. Chem. 277, 4906-10.

[17] Ikeda, O. et al. (2009) BS69 negatively regulates the canonical NF-kappaB activation induced by Epstein-Barr virus-derived LMP1. FEBS Lett. 583, 156774.

[18] Kurozumi, K., Nishita, M., Yamaguchi, K., Fujita, T., Ueno, N. and Shibuya, H. (1998) BRAM1, a BMP receptor-associated molecule involved in BMP signalling. Genes Cells 3, 257-64.

[19] Sekine, Y. et al. (2006) Modulation of TLR4 signaling by a novel adaptor protein signal-transducing adaptor protein-2 in macrophages. J. Immunol. 176, 380-9.

[20] Matsuda, T., Yamamoto, T., Muraguchi, A. and Saatcioglu, F. (2001) Cross-talk between transforming growth factor-beta and estrogen receptor signaling through Smad3. J. Biol. Chem. 276, 42908-14. 
[21] Atkinson, P.G., Coope, H.J., Rowe, M. and Ley, S.C. (2003) Latent membrane protein 1 of Epstein-Barr virus stimulates processing of NF-kappa B2 p100 to p52. J. Biol. Chem. 278, 51134-42.

[22] Eliopoulos, A.G., Caamano, J.H., Flavell, J., Reynolds, G.M., Murray, P.G., Poyet, J.L. and Young, L.S. (2003) Epstein-Barr virus-encoded latent infection membrane protein 1 regulates the processing of p100 NF-kappaB2 to p52 via an IKKgamma/NEMO-independent signalling pathway. Oncogene 22, 7557-69.

[23] Saito, N. et al. (2003) Two carboxyl-terminal activation regions of Epstein-Barr virus latent membrane protein 1 activate NF-kappaB through distinct signaling pathways in fibroblast cell lines. J. Biol. Chem. 278, 46565-75.

[24] Liao, G., Zhang, M., Harhaj, E.W. and Sun, S.C. (2004) Regulation of the NFkappaB-inducing kinase by tumor necrosis factor receptor-associated factor 3induced degradation. J. Biol. Chem. 279, 26243-50.

[25] Xie, P. and Bishop, G.A. (2004) Roles of TNF receptor-associated factor 3 in signaling to B lymphocytes by carboxyl-terminal activating regions 1 and 2 of the EBV-encoded oncoprotein latent membrane protein 1. J. Immunol. 173, 5546-55.

[26] Xie, P., Hostager, B.S. and Bishop, G.A. (2004) Requirement for TRAF3 in signaling by LMP1 but not CD40 in B lymphocytes. J. Exp. Med. 199, 661-71. 


\section{Figure legends}

Fig. 1. BS69 negatively regulates LMP1/CTAR1-induced NF- $\square$ B activation.

(A) Schematic diagrams of the domain structures of LMP1 and a deletion mutant (aa 1-

231) (B) $293 \mathrm{~T}$ cells $\left(1 \times 10^{7}\right)$ were transfected with HA-tagged BS69 (10 $\left.\square \mathrm{g}\right)$ with or without FLAG-tagged LMP1WT or a deletion mutant (aa 1-231) (10 \g). At $48 \mathrm{~h}$ after transfection, the cells were lysed, immunoprecipitated with an anti-FLAG antibody and immunoblotted with an anti-HA or anti-FLAG antibody. An aliquot of each TCL was immunoblotted with the anti-HA antibody. The asterisks indicate degradated protein bands derived from LMP1. (C) HeLa cells in 24-well plates were transfected with FLAG-tagged LMP1 (aa 1-231) (100 ng) and NF- $7 \mathrm{~B}-L U C$ (100 ng) and/or increasing amounts of HA-tagged BS69 (150 or $300 \mathrm{ng}$ ) using jetPEI. At $48 \mathrm{~h}$ after transfection, the cells were harvested and assayed for their luciferase activities using a Dual-Luciferase Reporter Assay System. An aliquot of each total cell lysate (TCL) was analyzed by immunoblotting with an anti-HA, anti-FLAG or anti-actin antibody. (D) HeLa cells in 24-well plates were transfected with a control siRNA or siRNAs targeting BS69 (\#1 and \#2) (15 pM). At $48 \mathrm{~h}$ after transfection, total RNA samples isolated from these cells were subjected to RT-PCR analysis usingBS69 or G3PDH primers. The BS69 expression levels were quantified by RT and quantitative real-time PCR analysis. Data represent the levels of BS69 mRNA normalized by that of G3PDH mRNA as an internal control and are expressed relative to the value at time zero. Data represent the means of duplicate PCR determinations, which generally varied by $<10 \%$. (E) HeLa cells in 24-well plates were transfected with a control siRNA or BS69 siRNAs (\#1 and \#2) (15 pM). The cells were then transfected with FLAG-tagged LMP1 (aa 1-231) (100 
ng) and NF- $\square$ B-LUC (100 ng) using jetPEI. At $48 \mathrm{~h}$ after transfection, the cells were harvested and the luciferase activities were measured. At least three independent experiments were carried out for each assay. ${ }^{*} \mathrm{p}<0.01$. An aliquot of each total cell lysate (TCL) was analyzed by immunoblotting with an anti-FLAG antibody.

Fig. 2. Reduction of endogenous BS69 enhances LMP1/CTAR1-induced IL-6 production and LMP1-induced non-canonical p52 processing. (A) HeLa cells in 12-well plates were transfected with a control siRNA or BS69 siRNAs (\#2) (20 pM). The cells were then transfected with FLAG-tagged LMP1 (aa 1$231 \mathrm{aa})(1.5 \square \mathrm{g}$ ) using jetPEI. At $48 \mathrm{~h}$ after transfection, total RNA samples were extracted and analyzed for their IL-6 mRNA expression levels by RT and quantitative real-time PCR analysis. Data represent the levels of IL-6 mRNA normalized by that of G3PDH mRNA as an internal control and are expressed relative to control siRNAtreated samples without LMP1. All values are the mean \pm SEM of triplicate cultures from three different experiments. ${ }^{*}, p<0.01$. An aliquot of each TCL was also analyzed by immunoblotting with an anti-FLAG antibody. (B) HeLa cells in 12-well plates were transfected with a control siRNA or BS69 siRNAs (\#2) (20 pM). The cells were then transfected with FLAG-tagged LMP1 (aa 1-231) (1.5 $\square \mathrm{g}$ ) using jetPEI. At $48 \mathrm{~h}$ after transfection, the culture supernatants were analyzed for IL-6 with ELISA. All values are the mean $\pm \mathrm{SEM}$ of triplicate cultures from three different experiments. ${ }^{*}, p<0.01$. (C) HeLa cells in 12-well plates were transfected with a control siRNA or BS69 siRNA (\#2) (20 pM). The cells were then transfected with HA-tagged LMP1 (1.5 $\square \mathrm{g})$ using jetPEI. At $48 \mathrm{~h}$ after transfection, the cells were lysed and fractionated into cytosol and nuclear fractions. An aliquot of both fractions were immunoblotted with anti-p52, anti-actin or 
anti-nucleoporin antibodies. (D) Human SKW6CL-4 B cells $\left(1 \times 10^{6}\right)$ were transfected with a control siRNA or BS69 siRNA\#2 (100 pM) using a MicroPorator according to the manufacturer's instructions. The siRNA-transfected SKW6CL-4 B cells were cultured for an additional $36 \mathrm{~h}$ and lysed. An aliquot of each TCL was analyzed by immunoblotting with the indicated antibodies. Total RNA samples were also extracted and analyzed for the BS69 mRNA expression levels by RT-PCR analysis.

Figure 3. TRAF3 is involved in BS69-medtated suppression of LMP1/CTAR1-induced NF- $\square$ B activation

(A) $293 \mathrm{~T}$ cells $\left(1 \times 10^{7}\right)$ were transfected with HA-tagged BS69 (10 $\left.\square \mathrm{g}\right)$ with or without FLAG-tagged TRAF1, TRAF2, TRAF3, TRAF5 or TRAF6 (10 \g). At $48 \mathrm{~h}$ after transfection, the cells were lysed, immunoprecipitated with an anti-FLAG antibody and immunoblotted with an anti-HA or anti-FLAG antibody. An aliquot of each TCL was immunoblotted with the anti-HA antibody. (B) HeLa cells in 24-well plates were transfected with a series of TRAFs $(30,100 \mathrm{ng})$ together with FLAG-tagged LMP1 WT $(100 \mathrm{ng})$ and NF- $\square \mathrm{B}-\mathrm{LUC}(100 \mathrm{ng})$ using jetPEI. At $48 \mathrm{~h}$ after transfection, the cells were harvested and the luciferase activities were measured. At least three independent experiments were carried out for each assay. ${ }^{*} \mathrm{p}<0.01 .{ }^{* *} \mathrm{p}<0.05$. An aliquot of each total cell lysate (TCL) was analyzed by immunoblotting with anti-FLAG or anti-actin antibodies. NS, Non-specific band. (C) HeLa cells in 24-well plates were transfected with a series of TRAFs (30, $100 \mathrm{ng})$ together with FLAG-tagged LMP1(aa 1-231) (100 ng) and NF- $\square$ B-LUC (100 ng) using jetPEI. At $48 \mathrm{~h}$ after transfection, the cells were harvested and the luciferase activities were measured. At least three independent experiments were carried out for each assay. ${ }^{*} \mathrm{p}<0.01$. ${ }^{* *} \mathrm{p}<0.05$. An aliquot of each 
total cell lysate (TCL) was analyzed by immunoblotting with anti-FLAG or anti-actin antibodies. NS, Non-specific band. (D) HeLa cells in 24-well plates were transfected with a control siRNA and/or BS69 siRNAs (\#2) and/or TRAF3 siRNA (15 pM). The cells were then transfected with FLAG-tagged LMP1(aa 1-231) (100 ng) and NF- $\square \mathrm{B}-$ LUC (100 ng) using jetPEI. At $48 \mathrm{~h}$ after transfection, the cells were harvested and the luciferase activities were measured. At least three independent experiments were carried out for each assay. ${ }^{*} \mathrm{p}<0.05$. An aliquot of each total cell lysate (TCL) was analyzed by immunoblotting with anti-FLAG, anti-TRAF3 or anti-actin antibodies. Total RNA samples were extracted and analyzed for their BS69 mRNA expression levels by RT-PCR analysis.

Fig. 4. BS69 directly interacts with TRAF3.

(A) Schematic diagrams of the domain structures of the TRAF3 deletion mutant fragments. (B) 293T cells (1x107) were transfected with HA-tagged BS69 (10 $\square \mathrm{g})$ with or without FLAG-tagged TRAF3 deletion mutants (10 $\square \mathrm{g})$. At $48 \mathrm{~h}$ after transfection, the cells were lysed, immunoprecipitated with an anti-HA antibody and immunoblotted with an anti-FLAG or anti-HA antibody. An aliquot of each TCL was immunoblotted with the anti-FLAG antibody. (C) Scheme of functional proposal of BS69 in the suppression of LMP1-induced NF- $\square \mathrm{B}$ activation. LMP1 consists N-terminal tail, six transmembrane domain and a long cytoplasmic C-terminal domain which contains two NF- $\square$ B activating domain, CTAR1 and CTAR2. BS69 directly interacts with LMP1 and suppresses LMP1-induced NF- $\square$ B activation through both CTAR1 and CTAR2. BS69 regulates CTAR1-medtated non-canonical NF- $\square$ B activation by interacting with TRAF3, and CTAR2-mediated canonical NF- $\square$ B activation by displacing TRADD from LMP1 
(17). LMP1-induced JNK activation is mediated by BS69 and TRAF6 (13). 

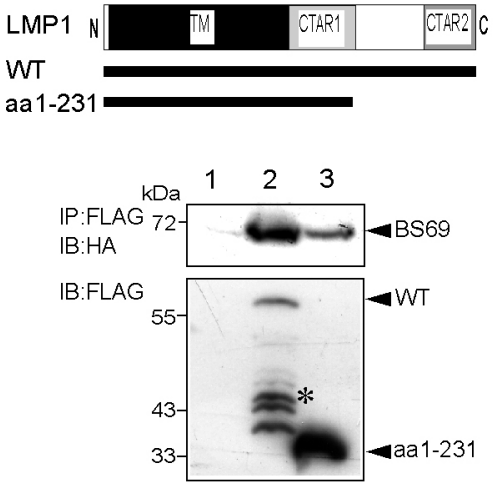

$\begin{array}{ll}\mathrm{TCL} & 72-\square \\ \mathrm{IB}: \mathrm{HA} & \square \mathrm{BS} 69\end{array}$

2 HA-BS69/FLAG-LMP1 WT

3 HA-BS69/FLAG-LMP1 aa1-231
1 HA-BS69

C

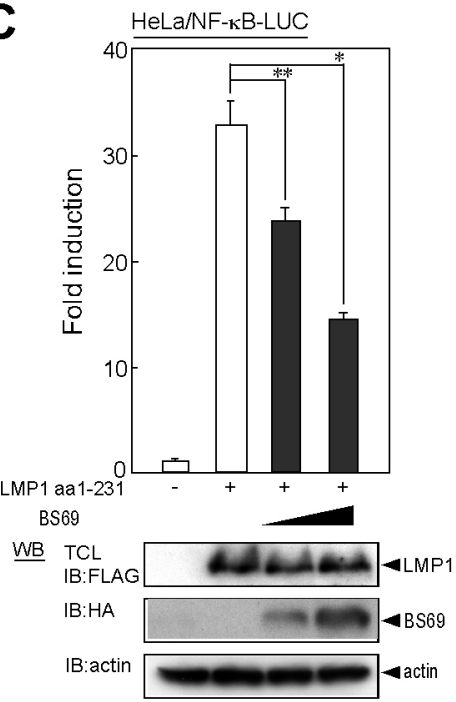

E
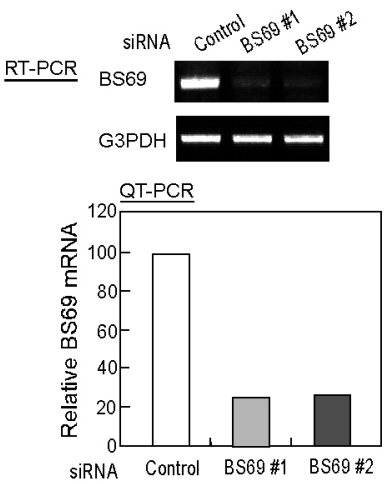

LMP1 aa1-231

$$
\text { BS69 }
$$

HeLa/NF-кB-LUC

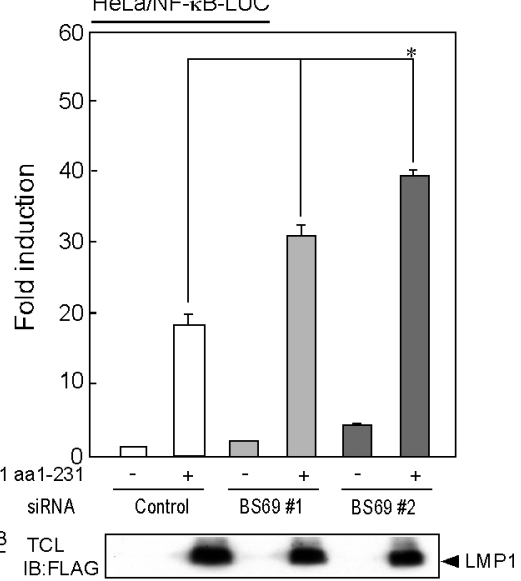


$\underset{\text { LMP1 aa1-231 }}{\operatorname{siRNA}} \frac{\text { Control }}{-+} \frac{\text { BS69\#2 }}{-++}$

$\underline{\text { RT-PCR IL-6 }}$

BS69

$N F-\kappa B 2$

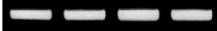

$\mathrm{G} 3 \mathrm{PDH}$

WB TCL

IB:FLAG

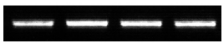

QT-PCR

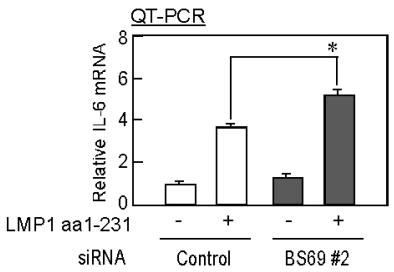

LMP1 aa1-231

siRNA

Cytosol
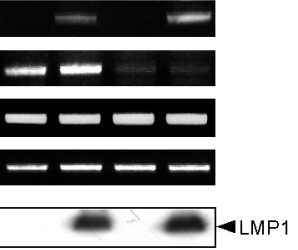
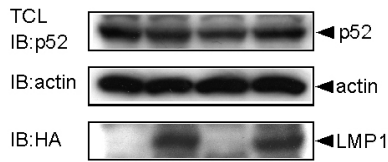

Nucleus

$$
\text { SiRNA } \frac{\text { Control }}{-+} \frac{\text { BS69\#2 }}{-+}
$$

TCL

IB:p52

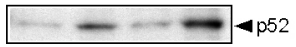

IB:nucleoporin
LMP1 aa1-231 siRNA

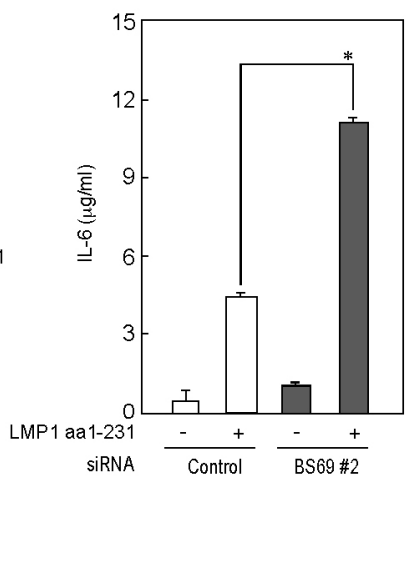

D

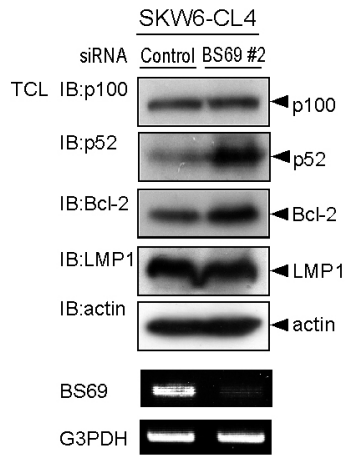
siRNA Control BS69 \#2

IB:p52

$\mathrm{B}: \mathrm{Bcl}-2$

IB:LMP1

IB:actin

nucleoporin 


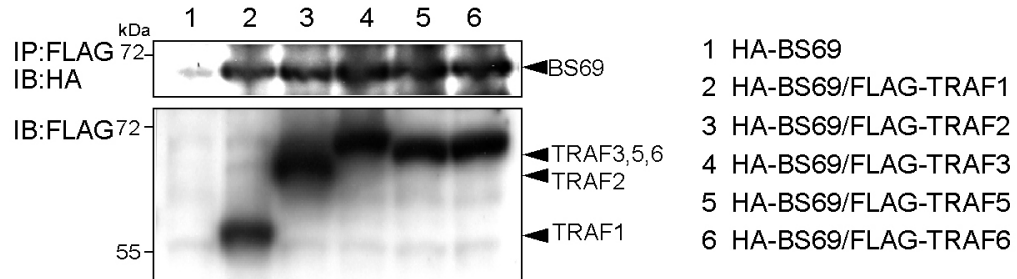

TCL

IB:HA
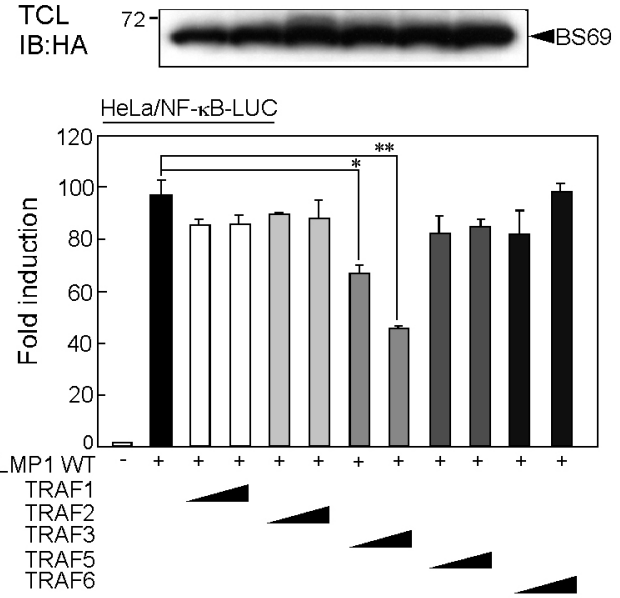

C

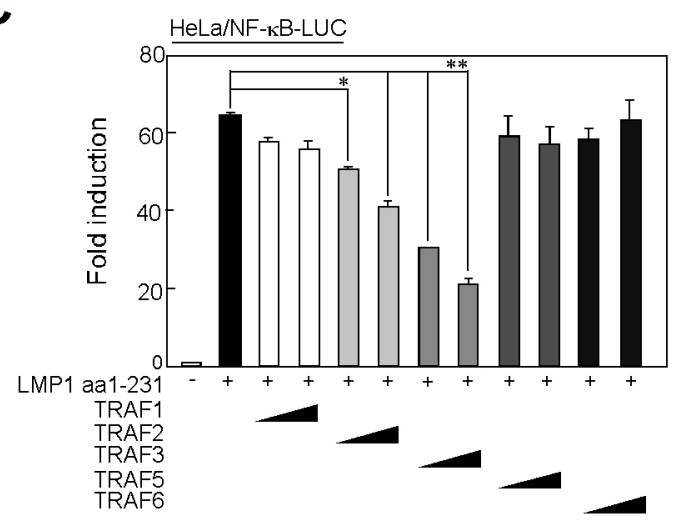

TCL IB:FLAG

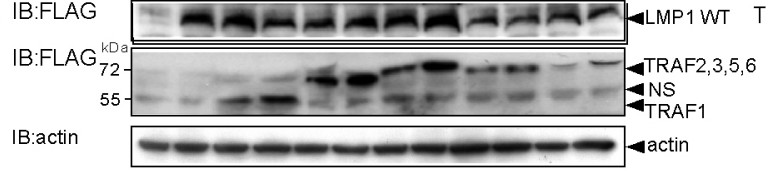

TCL IB:FLAG

IB:FLAG $G_{72}^{\mathrm{kDa}-}$

IB:actin
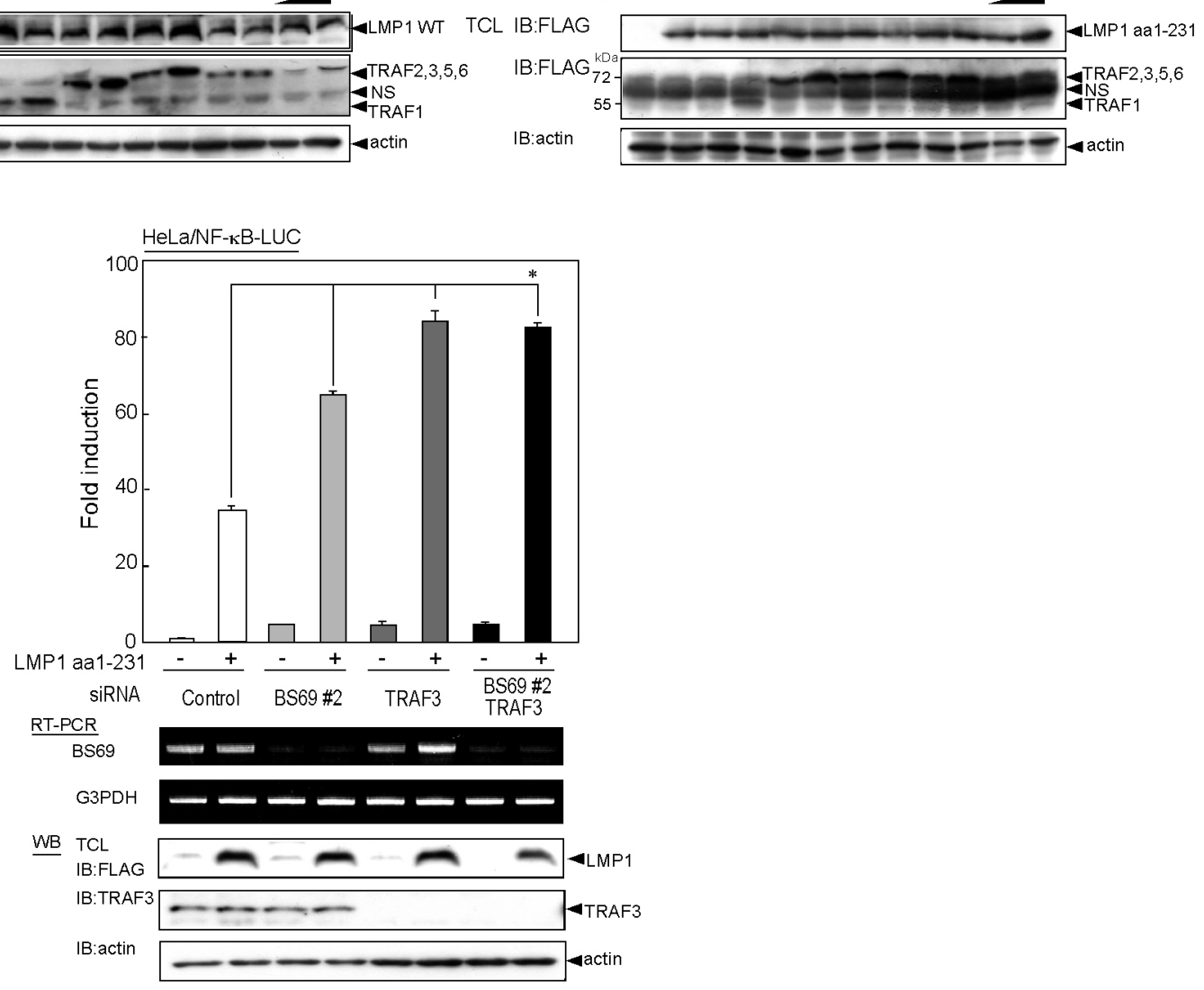

Figure 3 
TRAF3

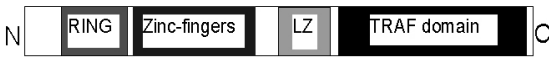

$\mathrm{FL}$

$\triangle 2-92$

$\triangle 2-190$

$\Delta 2-367$

$\triangle 422-568$

$\triangle 317-568$

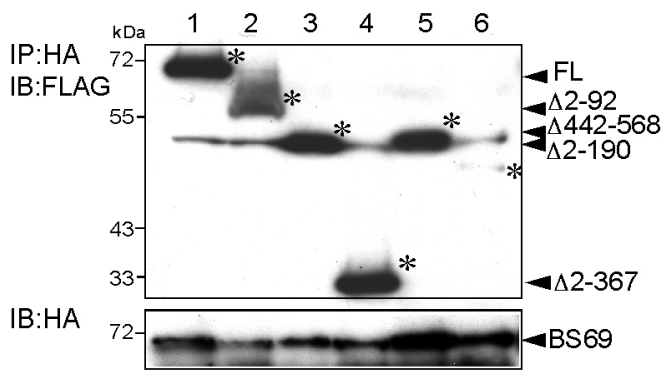

1 HA-BS69/FLAG-FL

2 HA-BS69/FLAG- $\triangle 2-92$

3 HA-BS69/FLAG- $\triangle 2-190$

4 HA-BS69/FLAG- $\triangle 2-367$

5 HA-BS69/FLAG- $\triangle 422-568$

6 HA-BS69/FLAG- $\triangle 317-568$

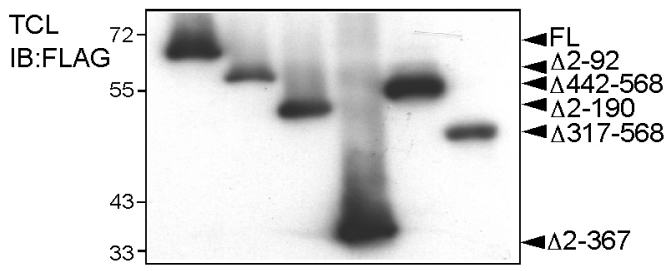

JNK pathway

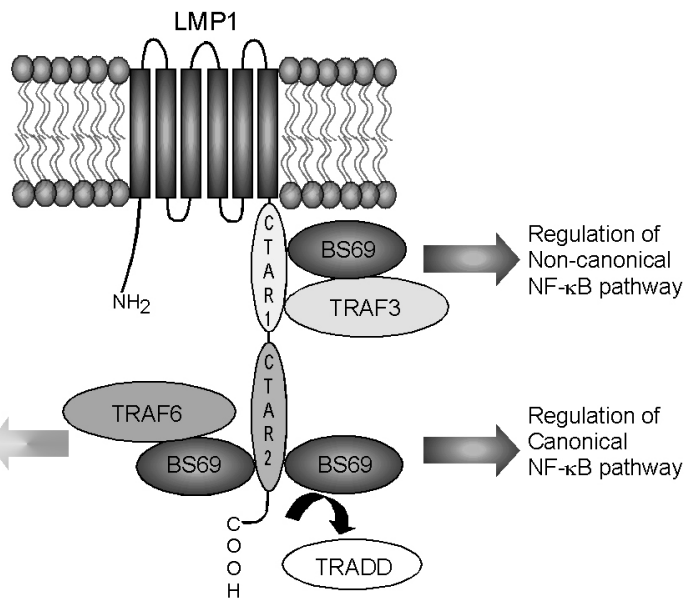

Figure 4 